\title{
О ТРЕБОВАНИИ ГУМАННОСТИ В ЖИЛИЩНОМ ПРАВЕ
}

\begin{abstract}
Аннотация: В статье анализируется требование гуманности применительно к действующим нормам жилищного законодательства. Автором предлагается рассматривать гуманность не только в контексте правоприменения, но и как основной принции жилищного права, а также обозначаются основные направления, по которым можно судить о гуманности норм жилищного законодательства.
\end{abstract}

Ключевые слова: Юриспрудениия, гуманность, гуманизм, принщип, требование, справедливость, жилье, выселение, права, аналогия

пецифика жилищных отношений должна оказывать существенное влияние на их правовое регулирование. В этой связи необходимо делать акценты на общественной значимости материального объекта (жилого помещения), выражающейся в поддержании физиологического функционирования человека, его социальной роли (функции в обществе) и места, в котором проходит его частная жизнь. В связи с этим, характерной чертой правового регулирования данных общественных отношений должен стать принцип гуманизма.

В жилищном законодательстве ссылку на требование гуманности мы встречаем всего один раз, когда речь заходит об аналогии права (ст. 7 ЖК РФ). Гуманизм и гуманность, безусловно, являлись и являются объектом для изучения представителей различных направлений научных знаний. Философские аспекты, исторические, социальные, но и, конечно же, правовые исследуются на протяжении многих веков и в той или иной степени влияют на современные правовые воззрения. В социальной философии акцент делается на обоснование сущности гуманизма и определению его роли в жизни современного общества ${ }^{1}$ вплоть до последовательного продвижения идеи о духовности и гуманистических традициях как основе нового формирующегося открытого общества, способных корректировать появляющиеся новые приоритеты и ценности в развитии человеческой цивилизации ${ }^{2}$. Философские воззрения позволяют выработать критерии, влияющие на соотношение действий (явлений, ситуаций, событий) в качестве гуманных и негуманных, определить

\footnotetext{
${ }^{1}$ См., например, Мелекаева И. К. Гуманизм и гуманные отношения в обществе. Автореферат дисс...к.ф.н., Ставрополь, 2004. 22 с. Наполнение категории гуманизма определенным содержанием зависело от исторического периода времени (от доктрины совершенного человека, через образ «святого», до девиза освобождения от пут феодализма и провозглашения свободы и равенства). В современный период гуманизм рассматривается через призму любви к человечеству, уважению достоинства и прав человека, ценности личности
}

${ }^{2}$ Ботвинова A.B. Духовность и гуманизм в открытом обществе. Автореферат дисс...д.ф.н. М., 2004. С. 4. критерии гуманности в данный конкретный исторический период развития общества. Интуитивно, обыденно гуманность можно определять через противопоставление: гуманно - негуманно (то есть жестоко, бесчеловечно). То есть гуманные ценности - это ценности, «вышедшие» из самой природы человека, его естества. Гуманно, что человек живет, для этого он должен есть, пить, где-то жить, гуманно иметь детей, а соответственно бесчеловечно (негуманно) лишать человека его жизни, средств к существованию, места проживания и т.д.

Следует несколько слов сказать о том, что ЖК РФ говорит именно о требовании гуманности, а не о принииие гуманности. На разное содержательное значение данных терминов обращается внимание в юридической литературе $^{3}$. Безусловно, что расхождения в содержательном значении данных терминов достаточно принципиальны. В рамках данной работы акцентировать внимание на данных различиях мы не будем, но заметим, что требование гуманности, содержащееся в ЖК РФ, адресовано только правоприменителю, а не участникам жилищных правоотношений. Вместе с тем, требование (гуманности) всегда должно быть адресовано участникам, а принципу (гуманности) должен подчиняться (помимо субъектов) и правоприменитель. Следовательно, правильней говорить не о требовании гуманности, а о принципе гуманности.

В юриспруденции гуманизм, как правило, исследуется с точки зрения основополагающего принципа юридической ответственности ${ }^{4}$, не часто речь ведется о гуманизме права в целом ${ }^{5}$, и совсем редко о гуманизме

\footnotetext{
${ }^{3}$ Более подробно о соотношении «требования» и «принципа» см.: Виниченко Ю.В. Разумность в гражданском праве Российской Федерации. Автореф...дисс. к.ю.н. 12.00.03. Санкт-Петербург, 2003. C. $11-12$

${ }^{4}$ Кашкина E.B. Гуманизм как принцип юридической ответственности. Дисс...к.ю.н., М., 2003. 187 с.

${ }_{5}^{5}$ Можно встретить утверждения о гуманизме общественных отношений (!), проявляющихся в том, что не только личность ответственна перед государством, но и государство перед личностью, и эта взаимная ответственность осуществляется на основе сотрудничества в решении конкретных задач (См.: Назаров Б. Л.
} 
как принципе соответствующей отрасли права ${ }^{6}$. Одним из проявлений гуманизма советского права (которое можно «переложить» на жилищное право) усматривалось в закреплении средствами права «распределения известной все возрастающей части материальных благ бесплатно (из общественных фондов) среди членов социалистического общества»7. Кроме того, например, Г. А. Свердлык предлагал рассматривать принцип социалистического гуманизма всего лишь в группе конституционных принципов, а не принципов собственно жилищно-правовых или общеотраслевых ${ }^{8}$. При этом гуманистическую сущность советского жилищного права он видел в установке на обеспечение жильем каждого советского гражданина", а проявлением гуманизма считал, в частности, нормы о предоставлении жилья во внеочередном порядке лицам, страдающими хроническими заболеваниями ${ }^{10}$. Вскользь упоминает о гуманизме содержания жилищных законов П. И. Седугин, когда говорит о принципах кодификации последних, а гуманистическую направленность Основ ${ }^{11}$ видит в сокращении случаев выселения граждан, в расширении гарантий прав лиц, проживающих в служебных помещениях и общежитиях ${ }^{12}$.

Как известно, большим противником общих принципов, заменяющих конкретные нормы закона, выступал И. А. Покровский. Боязнь субъективного усмотрения судей и одновременное признание существования объективных начал справедливости, культуры, добра приводит автора к мысли о введении данных норм в положительное законодательство ${ }^{13}$. Наверное, с позиции сегодняшнего

Конституционные правоотношения личности и государства // XXVI съезд КПСС и проблемы теории государства и права. М.: Изд-во ИГиП АН СССР. 1982. С. 172)

${ }^{6}$ Кондратюк Д.Л. Нравственно-правовые принципы в гражданском праве России (на примере справедливости, гуманизма, разумности и добросовестности). Дисс...к.ю.н., М., 2006. 170 с.

${ }^{7}$ Попоков В. Д. Гуманизм советского права. М.: Изд-во Моск. уни-та, 1972. С 73.

${ }^{8}$ Свердлык Г. А. Основы жилищного законодательства СССР и союзных республик и развитие принципов жилищного права // Основы советского жилищного законодательства: Межв. Сборник научн. трудов. Свердловск, 1981. С. 27.

${ }^{9}$ Там же. С. 29.

${ }^{10}$ Данные нормы сохранены и в новом ЖК РФ, однако, представляется, что современная их оценка носит несколько иной характер - это в первую очередь не забота о конкретном больном человеке, а способ защиты здоровья тех, кто находится рядом с ним, т.е. не нарушение прав и интересов других лиц

${ }^{11}$ Речь идет об Основах жилищного законодательства

${ }^{12}$ Седугин П. И. Право на жилище в СССР. М.: юрид. лит-ра, 1983. С. 28, 34.

${ }^{13}$ См.: Покровский И. А. Основные проблемы гражданского права. Изд. 3-е, стереотип. М.: Статут, 2001. С 102-103. (Классика российской цивилистики) дня, упреки И.А. Покровского законодателю были бы неуместны в том контексте, что подробное законодательное регулирование большинства жизненных ситуаций (мы в первую очередь говорим, конечно же, о жилищных отношениях) состоялось. Фактически речь идет о весьма незначительных, больше гипотетических примерах, рассчитанных на изменение фактических отношений и «отставание» законодательства от практики, где судьями и должны использоваться принципы добросовестности, справедливости, разумности и обсуждаемой гуманности. Таким образом, в рамках положительного жилищного законодательства гуманность рассматривается только в контексте правоприменения, как основа для формирования профессионального правосознания. В правоприменении - гуманность - есть основа для субъективного мнения судьи по каждому конкретному спору, который должен строить свое решение на основании тех философских и этических воззрений на содержание данного термина, на общепринятых моральных установках. Таким образом, судья обязан быть моральным человеком. По сути, закон предполагает существование на уровне профессионального (судейского) правосознания моральных и гуманных установок.

Здесь сделаем еще одно принципиальное уточнение - о соотношении терминов гуманность и гуманизм. Считается общепринятым, что гуманность - это одна из форм проявления гуманизма (это чувство, выражающееся в милосердии и сочувствии к человеку), а гуманизм - более широкое понятие, основанное, прежде всего, на уважении прав и свобод человека, гарантий их реализации. Таким образом, получается, что гуманность - это именно субъективное чувство судьи при принятии решения по конкретному жилищному делу, которая должна присутствовать только тогда, когда применяется аналогия права. Во всех других случаях предполагается, что принятый закон уже, по сути, есть проявление гуманизма. Гуманизм - это объективная категория, которая должна находить отражение в охране прав и свобод, в их реализации, т.е. в отношении к человеку ${ }^{14}$. Акцент так же делается на том обстоятельстве, что при рассмотрении гуманизма следует обращаться к условиям (выделено мной - С.И.), непосредственно определяющим развитие личности ${ }^{15}$.

В связи с эти, кроме гуманности в правоприменении, представляется, что нужно говорить о гуманизме жилищного права как его основном принципе. Регулирование жилищных отношений только через призму основных начал гражданского законодательства вряд ли приведет к желаемому социальному эффекту. Менее всего граждане готовы мириться с не-

\footnotetext{
${ }^{14}$ Кашкина Е.В. Указ. соч. С. 22.

${ }^{15}$ Попоков В. Д. Указ соч. С. 82.
} 


\section{Право и политика $2(158) \cdot 2013$}

справедливостью (по их мнению) именно тех законов, которые затрагивают их право на жилье.

Таким образом, гуманизм жилищного права, в первую очередь, должен быть выражен в субъективных жилищных правах лиц, в сокращении публично-правовых элементов в правовом регулировании жилищных отношений, в уменьшении субъективных жилищных обязанностей. Обозначим несколько основных направлений, по которым можно судить о гуманности норм жилищного законодательства.

Во-первых, гуманно создать такие условия для проживания людей, которые не только будут безопасны для их жизни и физического здоровья, но и создадут психологический комфорт для развития личности. Для этого разрабатываются определенные стандарты, предъявляемые к самому жилому помещению.

Во-вторых, гуманно вообще не выселять граждан из жилого помещения без предоставления другого жилья. На сегодняшний день в нашем законодательстве установлено четыре случая лишения права собственности за виновное поведение $\left(293\right.$ ГК + 29 ЖК РФ) ${ }^{16}$ и четыре же случая выселения без предоставления лиц, занимающих жилое помещение по договору социального найма (ст. 83 ЖК РФ). Не забудем про служебные жилые помещения и общежития, где исключений по сохранению права проживания осталось всего четыре. Здесь, думается, нужна очень четкая грань между принципом справедливости и гуманизма. По соотношению данных принципов высказано достаточно много различных мнений в юридической литературе. От практически их полного отождествления до принципиального расхождения. Тем не менее, большинство исследователей подчеркивают их глубокую взаимосвязь и переплетение и делают акцент на общечеловеческих ценностях, человеческом достоинстве, основных правах человека. Гуманно - не выселять, не закрывать глаза на то обстоятельство, что человек остается на улице и без жилища, право на которое гарантирует Конституция, но справедливо - защитить права и интересы третьих лиц, пострадавших от действий выселяемого (будь то нарушение общественного порядка, разрушение жилого помещения, или использования жилья не по назначению). Об этом говорят те, кто оценивает гуманизм не только в выражении интересов личности, но и общества. В этом смысле, справедливость должна быть найдена в соотношении различных субъективных жилищных прав, в предпочтении одних перед другими. «Существо социальной справедливости сводится к гармо-

\footnotetext{
${ }^{16}$ В этих случаях собственник должен получить денежную сумму, оставшуюся после всех установленных законом выплат, что можно рассматривать как проявление принципа недопустимости безвозмездного изъятия собственности, но только не гуманизма, поскольку приобрести на эти деньги другое жилое помещение фактически нереально.
}

ничному примирению личной свободы и благосостояния с благосостоянием человеческого общества» - писал В. М. Хвостов ${ }^{17}$. Общество должно учитываться эти личные потребности, однако пытаться не сталкивать интересы лиц. Справедливость права во всяком случае означает, что право не порождает массового протеста ${ }^{18}$.

Конфликт личных и общественных потребностей выражается сегодня и в следующих нормах жилищного законодательства: государственная потребность - избавиться от содержания обременительного жилищного фонда, индивидуальная потребность - получить в собственность жилые помещения пригодные для использования. В качестве конкретного примера такого конфликта выступает ситуация с капитальным ремонтом тех жилых помещений, которые были приватизированы гражданами.

В частности, напомним, что согласно Закону «О приватизации жилищного фонда в РФ» была разрешена приватизация жилых помещений, подлежащих капитальному ремонту, с сохранением за наймодателем обязанности по его проведению ${ }^{19}$. Разъяснение, которое дал Верховный Суд РФ по данному вопросу было таково, что ни один нижестоящий суд не рискнул взять на себя ответственность и удовлетворить законные требования собственников о капитальном ремонте их домов. Создать прецедент в данной области - это поставить под угрозу все бюджеты органов местного самоуправления, которые не смогут выполнить взятые на себя обязательства и потянуть такую финансовую нагрузку. Высшая судебная власть взяла на себя эту «ответственность» и дала разъяснение сложившейся правовой ситуации. Но настолько очевидна политическая и экономическая подоплека данного разъяснения, что, по сути, право в этой ситуации превращается в элемент решения этих вопросов с явным игнорированием закрепленного в Конституции РФ права на жилище.

В-третьих, государство должно не только гарантировать право граждан на жилище в смысле обеспечения им всех нуждающихся, но и создавать наиболее благоприятные условия сосуществования людей в жилых помещениях.

Вопиющим отступлением от принципа гуманизма является ситуация, сложившаяся в отношении права долевой собственности в жилых помещениях, которую

\footnotetext{
${ }^{17}$ Хвостов В. М. Основы социологии. Учение о закономерности общественных процессов. Элементарный Очерк. М., 1923. С. 86.

18 Лейст О. Э. Сущность права. Проблемы теории и философии права. М.: ИКД Зерцало-М, 2002. С. 93.

19 Дословно текст Федерального закона от 29.12.2004 N 189-Ф3 звучал следующим образом: «Приватизация занимаемых гражданами жилых помещений в домах, требующих капитального ремонта, осуществляется в соответствии с настоящим Законом. При этом за наймодателем сохраняется обязанность производить капитальный ремонт дома в соответствии с нормами содержания, эксплуатации и ремонта жилищного фонда» (ст. 16)
} 
не собирается решать законодатель, и не могут в связи с этим разрешить и судьи. Как известно, гражданское законодательство устанавливает применительно к долевой собственности принцип единогласия в принятии решений - это разумно и справедливо. Вместе с тем, огромное количество жилых помещений в настоящее время переходят по наследству в долях (и часто людям, находящимся в конфликте между собой), технический раздел таких помещений также достаточно часто невозможен. Люди вынуждены сосуществовать в таких объектах при отсутствии хоть какого-то правового выхода из этой ситуации (достаточно одного возражающего сособственника и ситуация фактически превращается в правовой тупик). Правовым решением данного вопроса в настоящее время выступает ст. 1168 ГК РФ, ст. 252 ГК РФ, а также возможность определить порядок пользования жилым помещением.

Определить порядок пользования в большинстве случаев или невозможно (например, для 1 комнатной квартиры невозможно в принципе, а для 2,3-х комнатных квартир при 5-10 сособственниках такое определение, мягко говоря, затруднено), либо не приводит к разрешению возникшего конфликта совместно проживающих.

Определенный выход из ситуации в рамках наследственных отношений предлагает ст. 1168 ГК РФ. Здесь четко следует понимать, что в рамках нотариального производства ее применение исключается. Наследник жилого помещения (неделимой вещи) может после оформления квартиры в долевую собственность обратиться в суд с требованием оформления данного объекта в свою индивидуальную собственность. Осложняется ситуация не только противоречивостью и непоследовательностью изложения самого п. 3 ст. 1168 на которые не раз обращалось внимание в юридической литературе ${ }^{20}$, но и сугубо практической ситуацией, когда жилое помещение является единственным имуществом, входящим в состав наследства.

Неприменимым на практике оказывается и абз. 2 п. 4 ст. 252 ГК РФ, поскольку, возражающий против выплаты компенсации за долю собственник, как правило, имеет «существенный интерес в использовании данного имущества».

Законодатель же продолжает оставаться на той же позиции - договаривайтесь между собой. Гуманно ли это? Думается, что вряд ли. Данная ситуация требует скорейшего правового разрешения путем использования инструментария жилищного законодательства. Во-первых, необходимо критерий проживания. Абсолютно очевидно, что сособственник, непосредственно проживающий в жилом помещении, должен иметь приоритет остаться в нем. Во-вторых, несмотря на значительность или не-

\footnotetext{
${ }^{20}$ См., например, Плеханова О.И. Наследование жилых помещений и имущественных прав, связанных с ними, в российском гражданском праве. Автореф...к.ю.н. 12.00.03. Иркутск, 2009. С. 8, 16.
}

значительность доли сособственника нужно установить его обязанность по отказу от своей доли в случае его не проживания, а также в случае наличия иных жилых помещений на праве собственности или иных законных основаниях. В-третьих, установить приоритет в праве на сохранение доли лицам, отнесенным к категории нуждающихся в жилье.

Нельзя в данном случае использовать только механизмы, характерные для гражданско-правового регулирования, что может привести (и уже приводит) как к негативным психологическим последствиям (ситуация постоянного конфликта и неразрешимой проблемы); к увеличению числа бытовых преступлений; к созданию «фактических» коммуналок, с существованием которых государство борется уже многие годы.

В-четвертых, правоприменение не должно формировать в массовом правосознании противоречащих действующему праву представлений о правомерном и неправомерном. Классическим примером тому в нашей действительности является ситуация с самовольными постройками. Вникать в правовые коллизии, связанные с данным вопросом мы не будем, хотелось бы акцентировать внимание на другом. Многие годы суды без каких-то видимых сложностей признавали права на самовольные постройки. В сознании людей сложился вполне устоявшийся стереотип поведения: нужно сначала построить, а потом идти в суд и постройку «узаконить». Большинство людей искренне считали (и некоторые и считают), что так правильно и законно поступать, что это не проще и выгодней, а именно правомерно. А потом без видимых для граждан причин ситуация в корне меняется. Гуманные по сути нормы (о самовольной постройке) при таком их применении превратились в ситуацию нескончаемых конфликтов. А ведь речь идет о жилье! Виновата в такой ситуации именно правовая система и непродуманное применение указанных норм.

И, наконец, в-пятых, жилищное законодательство должно оценивать не только соответствующее волеизъявление лица, но и условия формирования его воли.

Известно, что воля и волеизъявление всегда должны рассматриваться в единстве. «Единство воли и волеизъявления - основа для правовой оценки поведения субъекта и признания этого поведения имеющим юридическое значение - писал О.А. Красавчиков ${ }^{21}$. Все признают это утверждение применительно к обману, заблуждению и иным подобным основаниям, установленным для признания сделки недействительной. Однако, несмотря на социальную значимость отношений в жилищной сфере, в ЖК РФ есть примеры того, как законодатель не придает никакого значения воле и оценивает только волеизъявле-

\footnotetext{
${ }^{21}$ Красавчиков О.А. Категории науки гражданского права. Избран-
} ные труды: В 2 т. Т. 2. М.: Статут, 2005. С. 152. 


\section{Право и политика $2(158) \cdot 2013$}

ние, причем влекущее негативные для лиц последствия. Речь идет об отказе в принятии на учет лиц, если они в течение 5 лет совершили действия, влекущие к признанию их нуждающимися. Сегодня закон формально подходит к этим ситуациям. Если человек продал свою комнату или квартиру, то в течение установленного законом срока претендовать на постановку на учет он не сможет. А если эти действия явились следствием жизненной необходимости (тяжело заболел близкий родственник или необходимы средства для существования)? Подобные ситуации жилищное законодательство обязано учитывать, хотя бы в виде исключения предоставляя органам местного самоуправления принимать решения по каждому вопросу, исходя из конкретных жизненных обстоятельств. В противном случае подобные действия очень напоминают данную 100 лет назад трактовку административного принуждения или административного самоуправства, как ситуации того, что представителям власти нет надобности доказывать правомерность своего поведения ${ }^{22}$.

Таким образом, гуманизм в жилищном праве должен выражаться в максимально возможной защите интересов проживающих лиц (в независимости от правового основания проживания); в строго определенных основаниях выселения из жилого помещения, являющихся следствием прекращения определенных прав, как правило, связанных с виновным и недобросовестным поведением субъекта, либо по его собственной добровольной инициативе; в приоритете субъективных жилищных прав в ряде случаев над субъективным правом собственности. Гуманизм должен проявляться также в создании достойных условий проживания, в одинаковом (для идентичных категорий) и стабильном правовом положении лиц, занимающих жилые помещения, в последовательном применении норм жилищного законодательства на практике, в необходимости учета конкретных жизненных ситуаций.

\section{Библиография:}

1. Ботвинова А.В. [Текст] Духовность и гуманизм в открытом обществе / А. В. Ботвинова. Автореферат дисс...д.ф.н. - М., 2004. - 53 с.

2. Виниченко Ю.В. [Текст] Разумность в гражданском праве Российской Федерации / Ю.В. Виниченко. Автореф...дисс. к.ю.н. 12.00.03. - Санкт-Петербург, 2003. - 23 c.

3. Кашкина Е.В. [Текст] Гуманизм как принцип юридической ответственности / Е.В. Кашкина. Дисс...к.ю.н., - M., 2003. - 187 c.

\footnotetext{
${ }^{22}$ Куминера А. М Господство права и административное принуждение // Юридические записки. Вып. І. / под ред. А.П. Свирщевского, Г. С. Фельдштейна, А.Л. Фрейтап-Лоринговена, Ярославль, 1911. C. 8
}

4. Кондратюк Д.Л. [Текст] Нравственно-правовые принципы в гражданском праве России (на примере справедливости, гуманизма, разумности и добросовестности) / Д. Л. Кондратюк. Дисс...к.ю.н., - М., 2006. - $170 \mathrm{c}$.

5. Красавчиков О.А. [Текст] Категории науки гражданского права. Избранные труды: В 2 т. Т. 2./ О. А Красавчиков. - М.: Статут, 2005. - 494 с. (Классика российской цивилистики)

6. Куминера А. М [Текст] Господство права и административное принуждение // Юридические записки. Вып. І. / А. М Куминера; под ред. А.П. Свирщевского, Г. С. Фельдштейна, А.Л. Фрейтап-Лоринговена, Ярославль, 1911. - С. 1-50.

7. Лейст О. Э. [Текст] Сущность права. Проблемы теории и философии права / О. Э. Лейст- М.: ИКД Зерцало-М, 2002. - 288 с.

8. Мелекаева И. К. Гуманизм и гуманные отношения в обществе / И. К. Мелекаева Автореферат дисс...к.ф.н., - Ставрополь, 2004. - 22 с.

9. Назаров Б. Л. [Текст] Конституционные правоотношения личности и государства / Б. Л. Назаров // XXVI съезд КПСС и проблемы теории государства и права. -М.: Изд-во ИГиП АН СССР. 1982. - С. 170-173.

10. Плеханова О.И. [Текст] Наследование жилых помещений и имущественных прав, связанных с ними, в российском гражданском праве / О.И. Плеханова. Автореф...к.ю.н. 12.00.03. - Иркутск, 2009. - 20 с.

11. Покровский И. А. [Текст] Основные проблемы гражданского права. Изд. 3-е, стереотип / И. А. Покровский. - М.: Статут, 2001. - 354 с. (Классика российской цивилистики)

12. Попоков В. Д. [Текст] Гуманизм советского права / В. Д. Попоков - М.: Изд-во Моск. уни-та, 1972. -196 c.

13. Седугин П. И. [Текст] Право на жилище в СССР / П. И. Седугин. - М.: юрид. лит-ра, 1983. - 224 с.

14. Свердлык Г. А. [Текст] Основы жилищного законодательства СССР и союзных республик и развитие принципов жилищного права / Г. А. Свердлык // Основы советского жилищного законодательства: Межв. Сборник научн. трудов. - Свердловск, 1981. - C. 25-35.

15. Хвостов В. М. [Текст] Основы социологии. Учение о закономерности общественных процессов. Элементарный Очерк / В. М. Хвостов. - М., 1923. - 100 с.

\section{References (transliteration):}

1. Botvinova A.V. [Tekst] Dukhovnost' i gumanizm v otkrytom obshchestve / A. V. Botvinova. Avtoreferat diss...d.f.n. - M., 2004. - 53 s. 
2. Vinichenko Yu.V. [Tekst] Razumnost'v grazhdanskom prave Rossiyskoy Federatsii / Yu.V. Vinichenko. Avtoref... diss. k.yu.n. 12.00.03. - Sankt-Peterburg, 2003. - 23 s.

3. Kashkina E.V. [Tekst] Gumanizm kak printsip yuridicheskoy otvetstvennosti / E.V. Kashkina. Diss...k.yu.n., - M., 2003. - 187 s.

4. Kondratyuk D.L. [Tekst] Nravstvenno-pravovye printsipy v grazhdanskom prave Rossii (na primere spravedlivosti, gumanizma, razumnosti i dobrosovestnosti) / D. L. Kon dratyuk. Diss...k.yu.n., - M., 2006. - 170 s.

5. Krasavchikov O.A. [Tekst] Kategorii nauki grazhdanskogo prava. Izbrannye trudy: V 2 t. T. 2. / O. A Krasavchikov. - M.: Statut, 2005. - 494 s. (Klassika rossiyskoy tsivilistiki)

6. Kuminera A. M [Tekst] Gospodstvo prava i administrativnoe prinuzhdenie // Yuridicheskie zapiski. Vyp. I. / A. M Kuminera; pod red. A.P. Svirshchevskogo, G. S. Fel'dshteyna, A.L. Freytap-Loringovena, Yaroslavl', 1911. - S. 1-50.

7. Leyst O. E. [Tekst] Sushchnost' prava. Problemy teorii i filosofii prava / O. E. Leyst- M.: IKD Zertsalo-M, 2002. $-288 \mathrm{~s}$

8. Melekaeva I. K. Gumanizm i gumannye otnosheniya v obshchestve / I. K. Melekaeva Avtoreferat diss...k.f.n., Stavropol', 2004. - 22 s.
9. Nazarov B. L. [Tekst] Konstitutsionnye pravootnosheniya lichnosti i gosudarstva / B. L. Nazarov // XXVI s'ezd KPSS i problemy teorii gosudarstva i prava. - M.: Izd-vo IGiP AN SSSR. 1982. - S. 170-173.

10. Plekhanova O.I. [Tekst] Nasledovanie zhilykh pomeshcheniy i imushchestvennykh prav, svyazannykh s nimi, $\mathrm{V}$ rossiyskom grazhdanskom prave / O.I. Plekhanova. Avtoref...k.yu.n. 12.00.03. - Irkutsk, 2009. - 20 s.

11. Pokrovskiy I. A. [Tekst] Osnovnye problemy grazhdanskogo prava. Izd. 3-e, stereotip / I. A. Pokrovskiy. - M.: Statut, 2001. - 354 s. (Klassika rossiyskoy tsivilistiki)

12. Popokov V. D. [Tekst] Gumanizm sovetskogo prava / V. D. Popokov - M.: Izd-vo Mosk. uni-ta, 1972. - 196 s.

13. Sedugin P. I. [Tekst] Pravo na zhilishche v SSSR / P. I. Sedugin. - M.: yurid. lit-ra, 1983. - 224 s.

14. Sverdlyk G. A. [Tekst] Osnovy zhilishchnogo zakonodatel'stva SSSR i soyuznykh respublik i razvitie printsipov zhilishchnogo prava / G. A. Sverdlyk // Osnovy sovetskogo zhilishchnogo zakonodatel'stva: Mezhv. Sbornik nauchn. trudov. - Sverdlovsk, 1981. - S. 25-35.

15. Khvostov V. M. [Tekst] Osnovy sotsiologii. Uchenie o zakonomernosti obshchestvennykh protsessov. Elementarnyy Ocherk / V. M. Khvostov. - M., 1923. $-100 \mathrm{~s}$. 